\title{
Comparative Study of Effectiveness of Oral Acyclovir with Oral Erythromycin in the Treatment of Pityriasis Rosea
}

\author{
Amatya A, Rajouria EA, Karn DK
}

Department of Dermatology

Kathmandu University School of Medical Sciences

Dhulikhel Hospital Kathmandu Univeristy Hospital

Dhulikhel, Kavrepalanchowk, Nepal

\section{Corresponding Author}

Amit Amatya

Department of Dermatology

Kathmandu University School of Medical Sciences

Dhulikhel Hospital Kathmandu Univeristy Hospital

Dhulikhel, Kavrepalanchowk, Nepal

E-Mail: amitmax@yahoo.com

\section{Citation}

Amatya A, Rajouria EA, Karn DK. Comparative Study of Effectiveness of Oral Acyclovir with Oral Erythromycin in the Treatment of Pityriasis Rosea. Kathmandu Univ Med J 2012;37(1):57-61

\begin{abstract}
Background

Pityriasis rosea is an acute, self-limiting disease, probably infective in origin, affecting mainly children and young adults, characterized by distinctive skin eruptions and minimal constitutional symptoms. Both oral Erythromycin and oral Acyclovir have been used in its management.
\end{abstract}

\section{Objectives}

To compare the effectiveness of oral Erythromycin and oral Acyclovir in the treatment of Pityriasis rosea.

\section{Method}

Forty two patients with clinical diagnosis of Pityriasis rosea were enrolled. They were randomized into two groups. One group was given high-dose oral Acyclovir and another group oral Erythromycin in standard dose. The participants were evaluated one, two, four, six and eight weeks and six months after commencement of the study.

\section{Results}

Forty two patients including 26 males and 16 females completed the study. After 8 th week, all patients showed complete response in both the groups. The response to oral Acyclovir compared with that to oral Erythromycin was better and was statistically significant in 1st, 2nd, 4th and 6th weeks.

\section{Conclusion}

Although it is a self-limiting disease which resolves within three weeks to three months, this study reveals that both oral Acyclovir and oral Erythromycin are helpful in decreasing the severity and duration of Pityriasis rosea. Moreover, the study also indicates that oral Acyclovir is more effective than oral Erythromycin in reducing the severity and duration of Pityriasis rosea.

\section{KEY WORDS}

Acyclovir, Erythromycin, HHV-6, HHV-7, Pityriasis rosea

\section{INTRODUCTION}

Pityriasis rosea (PR) is an acute, inflammatory, self-limiting, papulosquamous disease of the skin..$^{1-4}$ Its onset is usually marked by the appearance of a herald patch (Fig. 1) which is an aymptomatic, single, thin, oval plaque with peripheral scaling present over the torso. After a week or two, similar but smaller and multiple lesions appear in a fir-tree pattern of distribution over the trunk. It may also present atypically. ${ }^{1}$ It is a common skin disease and is usually devoid of major constitutional symptoms but is presented to dermatology clinics with anxiety concerning the disease, variable pruritus and cosmetic disfigurement. ${ }^{1}$

An overall incidence of 0.68 per 100 dermatology patients was calculated with overall male to female ratio 1:1.43; the prevalence was reported to be $0.6 \%$ for young people aged between 10 and 29 years. ${ }^{5}$

Numerous studies suggest an infectious etiology for PR. ${ }^{6,7}$ Recent studies incriminate Human Herpes Viruses (HHV), mainly HHV7 and HHV6, as the causative agents. ${ }^{8-11}$ Studies are now focused on implementing antivirals such 
as Acyclovir, active against herpesviruses, in the treatment of PR. ${ }^{12-14}$ On the other hand, oral Erythromycin is a timetested drug which is reported to be beneficial to patients with PR. ${ }^{15}$ However, recent clinical experiences suggest macrolides, including Azithromycin and Erythromycin, are of no value in the treatment of PR. ${ }^{16,17}$

The aim of this study is to compare the effectiveness of empiric oral Erythromycin treatment with high dose oral Acyclovir targeting HHV7 and HHV6, in the management of PR.

\section{METHODS}

After approval from institutional review committee (IRC), an open randomized clinical trial was conducted in the Department of Dermatology, Dhulikhel Hospital, Kathmandu University School of Medical Sciences (KUSMS), from $18^{\text {th }}$ April 2010 to $18^{\text {th }}$ September 2011.

In all cases considered in this study, an informed consent was taken from every patient or patient's parent in case of minor.

The following diagnostic criteria of PR were used: ${ }^{18}$

Essential clinical features:

1. Discrete circular or oval lesions

2. Scaling on most lesions

3. Peipheral collarette scaling with central clearance on at least two lesions

Optional clinical features (at least one has to be present):

1. Truncal and proximal limb distribution, with less than $10 \%$ of lesions distal to mid-upper-arm and mid-thigh

2. Orientation of most lesions along direction of the ribs

3. A herald patch (not necessarily the largest) appearing at least two days before the generalized eruption

Exclusion clinical features:

1. Multiple small vesicles at the center of two or more lesions

2. Most lesions on palmar or plantar skin surfaces

3. Clinical or serological evidence of secondary syphilis

The peripheral collarette-scaling pattern of two or more lesions of PR in individual patients was observed and confirmed by Epiluminescence Dermatoscopy. ${ }^{19}$ Only patients with typical and generalized lesions of PR were included. Atypical presentation and cases with co-morbid skin conditions like psoriasis, eczema or mycosis were not included. Due to unavailability of internationally approved standardized scoring of severity of PR, the typicality and generalization of the disease was clinically judged. In each patient, the diagnosis and patient selection was agreed by two academic dermatologists.
In all patients, scales from a single PR lesion were subjected to $\mathrm{KOH}$ mount and were observed under low power and high power compound microscope for fungal elements and those cases in which such elements were seen were considered mycosis. All patients underwent Venereal Disease Research Laboratory (VDRL) test and those with positive results were subjected to Treponema Pallidum Haemagglutination Assay (TPHA) test. ${ }^{20}$ Patients who were reactive to either VDRL or TPHA tests were considered to have secondary syphilis and were excluded from the study.

Patients already on antibiotics, antivirals or long-term medication (e.g. for hypertension, diabetes, hypothyroidism etc) and patients with renal or hepatic impairment were excluded from the study. Pregnant or lactating women were also excluded from the study and so were patients with a known history of sensitivity to Acyclovir or Erythromycin.

Patients with clinical diagnosis of PR, fulfilling the above criteria, were selected from outpatient department of dermatology, Dhulikhel Hospital, KUSMS. The patients were prescribed either oral Acyclovir (Adults: $800 \mathrm{mg}$ five times a day; Children: $20 \mathrm{mg} / \mathrm{kg} /$ day in five divided doses; Maximum dose: four grams/day; Duration: seven days) or oral Erythromycin (Adults: 500 mg QID; Children: 40mg/ $\mathrm{kg} /$ day in four divided doses; Maximum dose: two grams/ day; Duration: seven days), randomly. All patients, with or without the complaint of pruritus, were also given oral antihistamine (Tab. Cetrizine 10mg OD HS for adults and children weighing more than $30 \mathrm{~kg}$ and Syrup Cetrizine $5 \mathrm{mg} / 5 \mathrm{ml}$ OD HS for children weighing less than and $30 \mathrm{~kg}$; Duration: seven days) and topical Class 4 (mid-strength) glucocorticoid (ointment Fluocinolone acetonide $0.025 \%$ twice daily application over lesions for seven days), for symptomatic relief. All prescriptions were standardized and the drugs were written in generic name. The patients were required to buy the medication from Dhulikhel Hospital Pharmacy. The drugs were available in closed packs with brand name and generic name with dose, manufactured date and expiry date printed on it. Since the study was open, the patient had full access to the information of the drug he or she was taking.

The patients were consulted after one and two weeks and then fortnightly after commencement of the study to evaluate response to treatment and after six months to detect any recurrences.

The responses were categorized as per the study performed by Eshani et al $^{13}$

- Complete response: No newer lesions. Disappearance of all previous lesions, with or without residual pigmentation.

- Partial response: Few newer lesions. Regression or disappearance of few previous lesions.

- No response: No improvement of older lesions. Appearance of newer lesions. 
Table 1. Demographic Characteristics of Patients.

\begin{tabular}{lll} 
Parameters & $\begin{array}{l}\text { Acyclovir group } \\
\mathbf{n}=\mathbf{1 8}\end{array}$ & $\begin{array}{l}\text { Erythromycin group } \\
\mathbf{n}=\mathbf{2 4}\end{array}$ \\
\hline Age & & \\
$<25$ years & 11 & 13 \\
\hline $25-35$ years & 6 & 9 \\
\hline 35 years & 1 & 2 \\
\hline Sex & 11 & \\
\hline Male & 7 & 15 \\
Female & & 9 \\
\hline
\end{tabular}

In total, 42 patients completed the study. The patients who received oral Acyclovir were assigned Group $A$ and those who received oral erythromycin Group B.

All the data were entered in MS Excel 2007. After transferring, data analysis was done by Statistical Package for Social Study (SPSS) version 16 utilizing Pearson chi square to find out the associations for significance at 0.05 level of confidence.

\section{RESULTS}

Forty two cases were included in the study. The mean age of the study group was $23.02 \pm 7.782$ years. (table 1 ) The youngest patient was two years old whereas the eldest was 40 years of age. Out of the 42 patients, 26 (61.9\%) were males whereas $16(38.1 \%)$ were females. Among the 42 patients included, 18 (42.9\%) were given oral Acyclovir (Group A) and 24 (57.1\%) were given oral Erythromycin (Group B). There was no significant difference between the demographic characteristics of the two groups. (Table 1)

Eight (19\%) out of 42 patients suffered dyspepsia during the first week of therapy. All the eight patients were in Group B (Erythromycin). However, all patients completed the full course of allocated medication and no additional medication was added.

Table 2. Response to treatment in both groups combined.

\begin{tabular}{|lllllll}
\hline Follow up & 1st week & 2nd week & 4th week & 6th week & 8th week & No recurrence \\
\hline No response & $6(14.3 \%)$ & 0 & 0 & $13(31.0 \%)$ & $6(14.3 \%)$ & 0 \\
\hline Partial response & $36(85.7 \%)$ & $32(76.2 \%)$ & $29(69.0 \%)$ & $36(85.7 \%)$ & $42(100 \%)$
\end{tabular}

Table 3. Comparison of response to acyclovir versus erythromycin.

\begin{tabular}{|c|c|c|c|c|c|c|c|c|c|c|c|}
\hline \multirow{2}{*}{$\begin{array}{l}\text { Follow up } \\
N=42\end{array}$} & \multicolumn{2}{|c|}{ 1ST WEEK } & \multicolumn{2}{|c|}{ 2ND WEEK } & \multicolumn{2}{|c|}{ 4TH WEEK } & \multicolumn{2}{|c|}{ 6TH WEEK } & \multicolumn{2}{|c|}{ 8TH WEEK } & \multirow{2}{*}{$\begin{array}{l}6 \text { MONTHS } \\
\text { RECURRENCE }\end{array}$} \\
\hline & NR & PR & PR & CR & PR & CR & PR & CR & PR & CR & \\
\hline Group A (18) & 0 & 18 & 11 & 7 & 1 & 17 & 0 & 18 & 0 & 18 & 0 \\
\hline Group B (24) & 6 & 18 & 21 & 3 & 12 & 12 & 6 & 18 & 0 & 24 & 0 \\
\hline p-value & \multicolumn{2}{|c|}{0.022} & \multicolumn{2}{|c|}{0.047} & \multicolumn{2}{|c|}{0.002} & \multicolumn{2}{|c|}{0.022} & & & \\
\hline
\end{tabular}

Group A: acyclovir, Group B: erythromycin, NR: no response, PR: partial response, CR: complete response, p-value: Pearson's chi square value 
complete response whereas only 18 out of 24 patients in group B had complete response. The remaining six patients in group $B$ were still in partial response. There was statistically significant difference in response to Acyclovir and Erythromycin in the sixth week also $(<0.05)$.

By the end of eighth week, all patients in both group $A$ and group $B$ had complete response.

All patients were followed up after six months of commencement of therapy and none of the patients from both group A and group B had recurrence of PR.

\section{DISCUSSION}

Most cases of PR occur between the ages of 10 and 35 years and it is uncommon in infancy, early childhood or old age. ${ }^{1}$ Consistently, in this study, the mean age was $23.02 \pm 7.782$ years (table 1 ). PR is slightly more common in females but, in this study males outnumbered females (table 1). ${ }^{1}$ This disparity may be due to limited sample size in our study. In a study done in Tehran, in which the sample size was 30 , the male to female ratio was one..$^{13}$

The skin lesions commonly fade after three to six weeks, but some clear in one or two weeks and a few persist for as long as three months. ${ }^{1}$ In this study, by the end of two months, all patients had complete response (Table 2). This implies that both Acyclovir and Erythromycin does reduce the duration of the disease.

Second attacks of PR occur in about $2 \%$ of cases after an interval of a few months or many years, and rarely, a partial or complete relapse of a fading eruption may be seen. ${ }^{1}$ In this study, no recurrence was seen by the end of six months suggesting that both Acyclovir and Erythromycin might prevent relapse of the disease. However, larger sample size and long term follow up studies are required to authenticate this statement.

In this study, oral Acyclovir was found to be superior to oral Erythromycin in reducing the severity and duration of PR (Table 3). Excepting one case, all patients taking oral Acyclovir had complete response within a month as opposed to two months for those taking oral Erythromycin. Similar results were seen in the study done by Eshani et al. who found that after eight weeks, the rate of complete response in patients who received high-dose Acyclovir was significantly higher than their matches who received oral Erythromycin. ${ }^{13}$ A placebo control trial done by Drago $\mathrm{F}$, et al. found that $79 \%$ of patients treated with oral Acyclovir had complete response compared with $4 \%$ of the placebo group by the end of second week of therapy..$^{12}$ In the present study however, only $38.8 \%$ (7 out of 18) patients treated with oral Acyclovir had complete response by the end of second week of therapy. The disparity in earlier resolution may be due to the difference in inclusion criteria in the studies. Our study included only those patients who had full blown lesions of PR whereas the study by Drago $\mathrm{F}$, et al. also included patients with initial or mild cases of

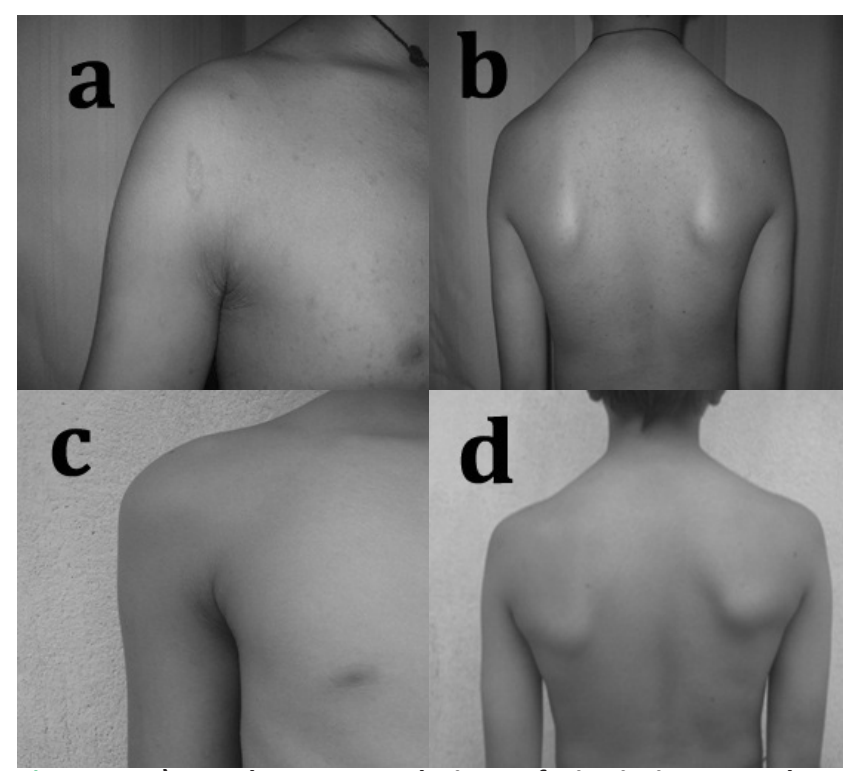

Figure 1. a) Papulosquamous lesions of Pityriasis rosea along with the herald patch. b) Fir tree pattern of distribution of the lesions over the back. c) Complete response after taking oral Acyclovir d) Complete response after taking oral Acyclovir.

PR. ${ }^{12}$

Many microorganisms have been incriminated for causing PR. Various fungi, bacteria like Streptococci, Spirochaetes (Borrelia spp), Legionella (L. longbeachae, L.micdadei, L. pneumophila), Chlamydia (C. pneumonia, C. trachomatis), Mycoplasma (M. pneumonia) and viruses such as Cytomegalovirus (CMV), Ebstein Barr Virus (EBV), parvovirus B19, picornavirus, influenza virus, parainfluenza virus have been studied but there is no evidence relating them with PR. ${ }^{1,2}$

Newer studies are focused on HHV7 and HHV6. Though no virus has been cultured from affected skin, virus-like particles were detected ultrastructurally over 40 years ago. ${ }^{21}$ Recent studies have found herpesvirus-like particles in $71 \%$ of PR lesions. ${ }^{22}$ Viral DNA of HHV7 and HHV6 is reported to be present in the peripheral blood mononuclear cells and lesional and unaffected skin of the majority of individuals with acute PR. ${ }^{23}$ With these scientific observations, PR can be considered as a viral disease caused by HHV7 and HHV6.

Acyclovir is an antiviral agent which works by inhibiting DNA synthesis and is variably active against different HHV. In practice, it is used in herpes simplex, chickenpox and herpes zoster. Besides dosage adjustment in renal failure, it is a well-tolerated drug. With the new knowledge that HHV7 and HHV6 are herpes viruses causing PR, it is logical to use oral Acyclovir for the condition. ${ }^{12}$

Erythromycin is a macrolide antibiotic primarily used as an antibacterial agent. It is also known to have antiinflammatory and immunomodulatory properties. Erythromycin has been used in PR after incidental observation of improvement in some patients with PR while receiving erythromycin. ${ }^{15}$

The main limitation to the study was the small sample 
size. Double blind studies, considering the effect size of the two therapies, following the instructions guided by the flowchart provided by CONSORT (Consolidated Standards of Reporting Trials) with larger sample size would further authenticate the results.

\section{CONCLUSION}

PR is nowadays considered a papulosquamous viral exanthema most probably caused by HHV7 and 6. Although it is a self-limiting disease which resolves within three weeks to three months, this study reveals that both oral Acyclovir and oral Erythromycin are helpful in decreasing the severity and duration of PR. Moreover, the study also indicates that oral Acyclovir is more effective than oral Erythromycin in reducing the severity and duration of PR. In this study, no untoward effect to oral Acyclovir was seen however, eight out of 24 patients taking oral Erythromycin complained of dyspepsia. Since oral Acyclovir is an antiviral agent effective against HHV and has high safety profile, its use in PR is strongly advisable.

\section{ACKNOWLEDGEMENT}

We would like to thank Mr. Sheshananda Sanjel for his assistance in statistical analysis.

\section{REFERENCES}

1. Burns $T$, Breathnach S, Cox N, Griffiths C. Rook's Textbook of Dermatology. 8th ed. In: Chap 33. Sterling JC. Virus Infections. Oxford: Wiley-Blackwell; 2010. p. 33.78-33.81.

2. Wolff K, Goldsmith LA, Katz SI, Gilchrest BA, Paller AS, Leffell DJ. Fitzpatrick's Dermatology in General Medicine. 7th ed. In: Chap 44. Blauvelt A. Pityriasis Rosea. New York: McGraw-Hill;2008.p.362-6.

3. James WD, Berger TG, Elston DM. Andrews' Diseases of the Skin Clinical Dermatology. 10th ed. In: Chap 11. Pityriasis Rosea, Pityriasis Rubra Pilaris, and Other Papulosquamous and Hyperkeratotic Disease. Philadelphia: Saunders Elsevier; 2006. p.208-9.

4. Burgdorf WHC, Plewig G, Wolff HH, Landthaler M. Braun-Falco's Dermatology. 3rd ed. In: Mrowietz $U$, editor. Papulosquamous Disorders. Munich, Lachem and Regensburg: Springer; 2009. p. 495-6.

5. Chuh A, Lee A, Zawar V, Sciallis G, Kempf W. Pityriasis rosea - An update. Indian J Dermatol Venereol Leprol 2005;71:311-5.

6. Burch PR, Rowell NR. Pityriasis rosea-an autoaggressive disease? Statistical studies in relation to aetiology and pathogenesis. $\mathrm{Br} J$ Dermatol 1970; 82:549-60.

7. Messenger AG, Knox EG, Summerly R, Muston HL, Ilderton E. Case clustering in pityriasis rosea: support for role of an infective agent. BMJ (Clin Res Edn) 1982; 284:371-3.

8. Chuh AA, Chiu SS, Peiris JS. Human herpesvirus 6 and 7 DNA in peripheral blood leucocytes and plasma in patients with pityriasis rosea by polymerase chain reaction: a prospective case control study. Acta Derm Venereol 2001; 81:289-90.

9. Watanabe $T$, Kawamura $T$, Jacob SE, Aquilino EA, Orenstein JM, Black JB. Pityriasis rosea is associated with systemic active infection with both human herpesvirus-7 and human herpesvirus-6. J Invest Dermatol 2002; 119: 793-7.

10. Broccolo F, Drago F, Careddu AM, Foglieni C, Turbino L, Cocuzza CE. Additional evidence that pityriasis rosea is associated with reactivation of human herpes 6 and 7. J Invest Dermatol 2005; 127:1234.

11. Drago F, Broccolo F, Rebora A. Pityriasis rosea: an update with a critical appraisal of its possible herpesviral etiology. J Am Acad Dermatol 2009 Aug; 61(2):303-18.

12. Drago F, Vecchio F, Rebora A. Use of high-dose acyclovir in pityriasis rosea. J Am Acad Dermatol 2006 Jan;54(1):82-85.

13. Ehsani A, Esmaily N, Noormohammadpour P, Toosi S, Hosseinpour $A$, Hosseini $M$. The comparison between the efficacy of high dose acyclovir and erythromycin on the period and signs of pitiriasis rosea. Indian J Dermatol 2010 Jul-Sep;55(3):246-8.

14. Rassai S, Feily A, Sina N, Abtahian S. Low dose of acyclovir may be an effective treatment against pityriasis rosea: a random investigatorblind clinical trial on 64 patients. J Eur Acad Dermatol Venereo 2011 Jan;25(1):24-6.

15. Sharma PK, Yadav TP, Gautam RK, Taneja N, Satyanarayana L. Erythromycin in pityriasis rosea: A double-blind, placebo-controlled clinical trial. J Am Acad Dermatol 2000;42:241-4.

16. Amer A, Fischer H. Azithromycin does not cure pityriasis rosea. Pediatrics 2006 Nov;118(5):2257-8.

17. Rasi A, Tajziehchi L, Savabi-Nasab S. Oral erythromycin is ineffective in the treatment of pityriasis rosea. J Drugs Dermatol 2008 7:35-8.

18. Chuh AA. Diagnostic criteria for pityriasis rosea - a prospective case control study for assessment of validity. J Eur Acad Dermatol Venereol 2003;17:101-3.

19. Chuh AA. Collarette scaling in pityriasis rosea demonstrated by digita epiluminescence dermatoscopy. Australias J Dermatol 2001;42:28890.

20. Young H. Guidelines for serological testing for syphylis. Sex Transm Infect 2000; 76:403.

21. Garcia E, Silva L, Gardner PS. Pityriasis rosea-a virological study. Br J Dermatol 1968;80:514-5.

22. Drago F, Malaguti F, Ranieri E, Losi E, Rebora A. Human herpes viruslike particles in pityriasis rosea lesions: an electron microscopy study. J Cutan Pathol 2002;29:359-61

23. Chuh AA, Chan PK, Lee A. The detection of human herpesvirus- 8 DNA in plasma and peripheral blood mononuclear cells in adult patients with pityriasis rosea by polymerase chain reaction. I Eur Acad Dermatol Venereol 2006;20:667-71. 